\title{
Sport, Health and Medicine: a sociological agenda
}

\begin{abstract}
This paper explores the ways in which social scientists should respond to the increasing prominence of health and medicine within sports science research agendas. It firstly reviews the research which has already been conducted on these themes identifying core bodies of work on pain and injury, sport and health, and the social organization of sports medicine. It then seeks to highlight the comparisons between the sociology of sport and the sociology of medicine, identifying existing areas of overlap and interchange between these two sociological subdisicplines. Finally it develops a research agenda for the future, consisting of more differentiated and nuanced understandings of sportspeoples’ illness/injury experiences, a development of critiques of the sport-health ideology which locate physical activity campaigns within public health more broadly, a scrutiny of the global inequalities which shape athlete health and illness, and an exploration of the impact of elite sports medicine on public health provision.
\end{abstract}




\section{Introduction}

There has been a fundamental change to the way in which sport, health and medicine have become linked in recent years. While the basic connection is centuries old (Berryman, 2010), the frequency and force with which citizens are urged to take part in physical activity and exercise in order to improve their health, to reduce morbidity and mortality rates, has increased at an exponential rate. Although most acute in Western nations, this is an international phenomenon. For instance, in 2003 the United Nations General Assembly adopted 'Resolution 58/5: Sport as a Means to Promote, Health, Education and Peace' which pronounced that 'Sport and play improve health and well-being, extend life expectancy and reduce the likelihood of several non-communicable diseases ... Regular physical activity and play are essential for physical, mental, psychological and social development' (cited in Safai, 2008).

Alongside the consumption of food, alcohol and tobacco, physical activity constitutes one of the four pillars of public health promotion (Lupton, 1995). The evidence in support of this position is quite startling, with one article recently published in the British Medical Journal claiming that 'exercise and many drug interventions are often potentially similar in terms of their mortality benefits in the secondary prevention of coronary heart disease, rehabilitation from stroke, treatment for heart failure, and prevention of diabetes' (Naci \& Ioannidis, 2013, p. 1). This has led to public health campaigns such as the 'Exercise is Medicine' initiative launched by the American Medical Association and the American College of Sports Medicine in 2012. ${ }^{1}$ But these policies must also be understood in light of perceptions about low levels of physical activity in contemporary society which are depicted using the alarmist rhetoric of 'a global pandemic' (Piggin \& Bairner, forthcoming).

For those working in faculties of sports science/kinesiology the changes are encountered on a day-to-day basis. Just as sociologists of sport have looked to their parent 
discipline for validation and legitimization (Malcolm, 2012), so sports physiologists have sought recognition from firstly human biologists, and latterly medicine, the profession which practically applies that knowledge and wields considerable social influence as a result. The shift from a 'sport' to a 'health' research agenda has been facilitated by the relative availability of research funding (following the global economic crisis there has been a concentration of resources to 'core' activities such as public health and medicine) and precipitated by critiques of the validity of sports science (a UK Inquiry into the standing of sports science conducted by the House of Lords (2012, p. 4) damningly concluded that small sample sizes and the absence of suitable control groups meant that 'sport and exercise science research on elite athletes is generally observational and anecdotal'). As a consequence sport and exercise science is becoming increasingly medically-oriented; a development which has major implications for those working in the social sciences of sport.

Social scientists need to consider how they can and should respond to this new research environment. While any such engagement brings with it a myriad of opportunities, it also contains a number of identifiable threats. Consequently this paper highlights existing research and explores potential developments in this field. The aim is to take stock of what has been achieved and to consider how new avenues of research could be structured. The paper looks at both the strengths of this work as well as exploring what can be learnt from the adjacent field of the sociology of medicine/health and illness, ${ }^{2}$ both in terms of theoretically driven empirical research, and the politics of interdisciplinary working. It does so through the lens of a critical social science, exploring everything from the interpersonal relations that characterize lay-medical interaction to the macro-political context of policy development and its global implications. In so doing it helps develop a sociology of sport which can 'highlight aspects of the general human condition' and make the world 'less wasteful of lives and 
resources' through debunking popular myths about sport, and critically appraising the actions of those more powerful groups involved in sport. ${ }^{3}$

\section{The sociology of sport, health and medicine: a review}

As I have argued elsewhere, a review of textbooks, readers and journals pertaining to the sociology of medicine reveals a dearth of studies related to sport (Malcolm \& Safai 2012). As a consequence, in order to reveal the extent of existing research one needs to look primarily at the work produced by those who more closely identify with 'sports studies'. In this respect one can usefully identify three core bodies of work: experiences of pain and injury, political ideologies linking sport and health, and the organization of sports medicine.

\section{Sport, pain and injury}

Sociologists of sport started looking at aspects of sport, pain and injury in the early 1990s (though Kotarba’s (1983) study of Chronic Pain, which included a chapter on sport, preempted this development by some time). Pioneering researchers included Messner (1992), Nixon (1992), and Young (1993). Much of this early work focused on the cultural and organizational parameters of sport (Hughes \& Coakley 1991; Messner, 1992; Nixon, 1992; Young, 1993) which shape the lived experience of pain and injury (Young \& White, 1993; Young et al., 1994), and thus culminate to lead pain and injury to be viewed in particular ways. Some of these works were centrally informed by the then nascent 'sociology of the body', others were primarily influenced by considerations of gender, and the study of masculinities in particular. Some were informed by both.

Publication of Young's (2004) Sporting bodies, damaged selves: sociological studies of sports related injuries, and Loland et al.’s (2006) Pain and injury in sport: social and ethical 
considerations indicated something of the maturation of this area in the mid-2000s, with the formation of a critical mass of researchers and published studies. By this time it became broadly accepted that sports subcultures are frequently characterized by the normalization of relatively high degrees of tolerance towards pain and injury and the stigmatization of those who are deemed to be overly/inappropriately influenced by injury concerns (Roderick, 2006). Further studies have shown that athletes are particularly inclined towards self-treatment (Atkinson, 2007; Pike, 2005) and treatment shopping (i.e., consulting various medical personnel until the athlete finds the prognosis/diagnosis they hoped for). Athletes show pronounced levels of negotiation over treatment, a propensity to question the expertise of clinicians (Thing, 2012), and/or a tendency to simply avoid consultation outright (Malcolm, 2009). While some practices appear to be specific to the particular context/sport, British and North American sport have largely produced similar results, and the differences identified between male and female experiences of pain and injury in sport appear minimal (Young \& White, 1993). There is, however, some disagreement over whether elite and non-elite athletes respond in similar ways (Liston et al., 2006; Pringle \& Markula, 2005).

\section{Sport and health}

It was partly as a consequence of the emergence of this literature, but partly also due to the development of studies of doping in sport which moved beyond ethical debates and began to focus on the social processes underlying such practices (Waddington \& Murphy 1992), that examinations of the broader sport-health ideology began to emerge. As befitting a critical discipline such as sociology (Berger, 1963), these studies have sought to expose the contradictions within this set of beliefs and their abstraction from social practice.

The first overview of this area (Waddington, 2000) identified both the long history and the international spread of public policy statements promoting physical activity and 
health, as well as the recent growth in physiological evidence which indicates that exercise contributes positively to health. It then questioned the veracity of the sport-health ideology, identifying the common conflation of exercise and sport in these policies, and arguing that their respective health consequences are quite distinct. Thus, while exercise may contribute to improved health, Waddington (2000) demonstrates that sport is an inherently competitive activity which entails distinct social relations, that it is infused with aggressive masculinity and thus a relatively high tolerance of violence and, consequently, that injury and pain are not infrequent occurrences (as evidenced in the research cited above). The sport-health ideology is further exposed by patterns of commercial sponsorship. At the end of the twentieth century criticism focussed on the appropriation of sport by alcohol and tobacco companies whereas now, due to legislative changes, concern is more frequently raised over the way companies such as McDonalds and Coca Cola seek to associate themselves with sporting events. As Waddington (2000) identifies, a major outcome of the sport-health ideology is to individualize responsibility for health affairs which leads to victim blaming of those who 'fail' to exhibit the self-discipline required to systematically use physical activity for healthful purposes.

Scambler (2005) extends this analysis by placing a greater emphasis on the way money and power corrupt the health promoting properties of sport in an era of 'global' or 'disorganized capitalism'. He outlines how the sport-health ideology is disrupted by the increasing competitiveness of sport, the disjuncture between health and physical education policies (i.e. at the same time that people are being urged to exercise more, educational provision for physical activity is contracting), and the importance of consumerism and identity to contouring exercise participation. These factors, alongside the use of performanceenhancing drugs, suggest that disorganized capitalism has enabled developments in sport which are ‘antithetical as well as favourable to health' (Scambler, 2005, p. 84). He concludes 
that sport and health is one example of the way that contemporary public policies are 'designed as much to secure public legitimation as to be effective’ (Scambler, 2005, p. 92).

Safai's (2008) contribution adds to this analysis by drawing attention to the 'social determinants of health’ (Wilkinson \& Marmot 2003) and exploring the provision of sports medicine. She notes that sport and health promotion policies frequently neglect the barriers which exist for disadvantaged and marginalized populations and obscure the extent to which health is contoured by the way resources are organized and distributed within society. She

subsequently outlines the role of sports medicine practitioners in mediating the relationship between sport and health (further explored in the next section) before concluding by questioning how the economic interests of the 'sports medicine industry' lead to a focus on the more profitable areas of treatment and rehabilitation, and the concomitant neglect of injury prevention. Indicative of the growing critique of the conceptual link between sport and health, a recent meta-analysis of the healthiness of the youth behaviour concluded that young athletes are more likely than non-athletes to participate in unhealthy activities, such as the consumption of alcohol and use of steroids (Diehl et al., 2012)

\section{The social organization of sports medicine}

Research on the social organization of sports medicine is the most recent of these three areas to emerge. A variety of contexts have been explored. Walk (1997) and Safai (2003) focussed on the sports medicine provision in college sport in North America, while Kotarba looked at medical provision in male rodeo and wrestling (2001) and female football (2012) in the US, and Theberge (2008; 2009) conducted research with the clinicians employed to service Canada's elite national athletes. In the UK, Waddington (2000; Waddington \& Roderick 2002) and Malcolm (2006; Malcolm \& Sheard 2002) led studies of the role of doctors and physiotherapists practicing in English professional football and rugby union clubs 
respectively, and Scott (2012) examined the doctors and physiotherapists working with Britain’s Olympic athletes in the run up to London 2012. Most recently Bundon and Clarke (2012) have explored how Canadian elite athletes are encouraged and/or restricted from using Complementary and Alternative Medicine (CAM), while Kerr (2012) has discussed how sports scientists more generally experience integration into elite sports environments.

This work has largely been organized around three themes. First, research has focussed on the broad idea, originally expressed by Walk, 'that medicine is practiced differently, more competently, and/or more ethically in nonsports contexts' (1997, p. 24). Medical staff in professional sport accept, or are resigned to the fact, that their athletepatients are far less likely to comply with their recommendations than are the patients they see in their 'normal' working lives. These considerations may lead to compromised prognoses and even diagnoses and research indicates that clinicians develop specific strategies accordingly (Malcolm, 2006; 2009). The medical provision in elite sport may therefore be of a poorer quality than that provided to the general public (Waddington, 2000).

This 'peculiarity' extends to the deployment of medical ethics in the sports context, where clinicians may find that their primary responsibility towards the athlete-patient is compromised by a loyalty to the individual manager, team or organization which employs them. This leads Edwards \& McNamee (2006) to question whether sports medicine should, ethically speaking, even be considered a form of medicine as its focus on performance places it beyond a discipline defined by the pursuit of human health. Sociological research, however, has established that clinicians tend to accept breaches of patient confidentiality and may, on occasion, seek to justify their own clear infringement of such regulations when practicing in professional sport (Malcolm \& Scott 2013; Waddington \& Roderick 2002). To this end Kotarba (2001) explicitly positions sports medicine as a form of occupational medicine (though it should be noted that this is no mitigation for ethical breaches). 
Second, researchers have examined the degree to which sports clinicians are required to balance the sometimes conflicting considerations of health and performance (Safai, 2003; Scott, 2012; Theberge, 2007). The strength of Nixon's (1992) early contention, that 'sportsnets' effectively conspire to coerce athletes to play with injury and through pain, has been broadly challenged. Indeed an alternative view is offered by Safai (2003) who emphasizes the 'culture of precaution' amongst medical staff at a Canadian university. However, while there may be counterbalances, the broad consensus is that the 'culture of risk' evident in elite professional sport in particular is predominant.

Finally, research has explored the relations between different health professionals practicing in sport. Malcolm (2006) identified the importance of occupational boundaries with physiotherapists on the status of club doctors in English rugby union, Safai (2007) explored the demise of the Sports Medicine and Science Council of Canada within a context of professional tensions over inclusion/exclusion, and Theberge (2008; 2009) has discussed the blurred occupational boundaries between, and the jurisdictional narratives used by, athletic therapists, physiotherapists and chiropractors working with Canadian elite athletes. Most recently Scott (2012) and Malcolm \& Scott (2011) have examined the impact of policy and organisational changes upon professional relations between doctors and physiotherapists who provide medical support for UK Olympic athletes.

\section{Principles of a research agenda: integrating the sociologies of sport and medicine}

While the study of sport and exercise might be relatively marginal to the sociology of medicine, we can nevertheless take some important pointers from the structure of this subdiscipline in considering how a sociology of sport, health and medicine might develop in future. For instance, in Medical Power and Social Knowledge, Bryan Turner (1995) argues that a comprehensive sociology of health and illness must cover three levels of analysis: the 
individual, or perceptions of healthcare; the social, or the construction of the categories of disease and health care organizations; and the societal, or healthcare systems in their political context. Albrecht et al. (2000) use a similar typology to structure their Handbook of Social Studies of Health and Medicine focussing on: the social processes which shape health risks and perceptions of health; health and illness experience; health care systems and practice. Nettleton (2006) provides a broader sketch, but one which ultimately diverges little from the pattern identified already. She argues that the broad structure of the sociology of health and illness consists of: the analysis of medical knowledge; lay perceptions and experiences of health and illness; social and cultural aspects of the body; the patterned nature of health and illness in relation to the wider social structure, and the social organization of informal and formal health care. The medical sociology section of the American Sociological Association defines the area's central topics as, 'the subjective experience of health and illness, political, economic and environmental circumstances fostering ill health; and societal forces constraining the medical care system and individuals’ responses to illness. ${ }^{4}$

We can see from the above that, to a greater or lesser extent, sociological research on sport, health and medicine broadly correlates with the general structure of the sociology of medicine. The initial and perhaps still the primary focus has been on the individual - the health and illness experiences and responses of sportspeople (pain and injury) - but this has been accompanied by examination of the social - research exploring healthcare practice in sport, if not so much the political, economic and environmental factors which shape access to healthcare (the social organization of sports medicine) - and explorations of the societal - the political context of sport and health promotion (critiques of the sport-health ideology).

Furthermore we can see the penetration of ideas gleaned from the sociology of medicine into the research on sport through the citation of a number of seminal works. For instance, Waddington \& Murphy’s (1992) study of drug use in sport first introduced notions 
of medicalization (Illich, 1975; Zola 1972) to the sociology of sport, ${ }^{5}$ and this idea has continued to underpin critiques of the sport-health ideology. Studies of pain and injury have drawn on the illness experience literature produced by Kathy Charmaz (Roderick 2006; Sparkes \& Smith 2002), Arthur Frank (Sparkes \& Smith 2002), Julius Roth (Roderick, 2006) and others. Roderick (2006) and Malcolm (2009) have both explored the literature on uncertainty in their studies of athletes' reactions to lay-medical interaction. Thing (2012) draws on concepts of trust ('docile bodies') and the democratization of expert knowledge ('reflexive users') to understand patients' experiences of medical treatment. Others have drawn on ideas about medical dominance, and in particular Eliot Freidson's work on the power of the medical profession (Malcolm, 2006; Safai, 2003; Waddington, 2012; Walk, 1997). Literature which explores the jurisdictions and boundaries between different professional groups has similarly been cited and developed (Malcolm \& Scott 2011; Theberge, 2008, 2009).

But in pointing out these comparisons I am not simply arguing that sociologists of sport should transpose the workings of the sociology of medicine onto sport. There are both some problems within the sociology of medicine that social scientists of sport would do well to avoid (noted in the conclusion to this article), and there are some distinct characteristics about the medical aspects of sport of which we should be cognisant. With regards to the latter we need, firstly, to be aware of the specific time and space in which sports medicine has developed. Although this varies from country to country, sports-specific medical specialisms have generally been established some considerable time after their 'parent' discipline began to be structured, with professional bodies, formal educational qualifications, and the status to practice state-regulated. Sports medicine is only now developing the structural features of the broader medical profession and so is characterized by relatively weak occupational groupings and a degree of contestation over areas of expertise (Malcolm, 2006). Because of the 
particular time and space in which sports medicine is emerging practitioners are, for instance, relatively receptive to multidisciplinary healthcare teams in which different professions (most notably physiotherapy and chiropractice, but also sports/athletic training, masseurs, etc.) work together as relatively equal social groups (Malcolm \& Scott 2011; Theberge, 2009).

Second we need to be aware of the particular contingencies which shape the way athletes respond as patients. In this regard we might consider the specific time-related considerations of injured athletes (Roderick, 2006). Briefly put, sportspeople may be particularly keen to 'recover' from injuries and thus may have a very specific conception of what speed of recovery is acceptable. 'Rest' as a form of treatment is often the option of last resort (Pike, 2005). Timing considerations may be related to particular sporting events (e.g. many athletes have only one chance of participation in an Olympic Games), the extent to which an athlete's livelihood (and often also access to healthcare) are closely linked to athletic performance, and/or the symbiotic nature of athlete identity and participation in training and competition. The differences identified here may not be differences in kind, but they are certainly differences of degree.

Thirdly and perhaps most significantly, we should consider how this lay group's medical knowledge distinguishes sportspeople from other 'patients'. The increasing knowledge of patients, often derived from the internet but increasingly institutionalized by state policies designed to enable greater patient involvement in the organization of medicine (see Martin \& Finn 2011 for a discussion of the dynamics of these relationships) has been noted as a fundamental characteristics of medical care more generally in the twenty-first century (Thing, 2012). However, for a number of reasons one could argue that the influence of athletes' lay medical knowledge is qualitatively distinct (Malcolm, 2006). Groups of athletes are likely to experience the same kinds of injuries because they basically share the same environmental conditions. They have regular interaction with each other because they 
share the same training environment, travel and play as a team, and often see each other socially as well. The frequency of injury also means that players share a relatively long-term chronic prognosis. While these contextual factors enable lay medical knowledge to become increasingly coherent, a further inherent characteristic of being an elite athlete - the continual and varied experimentation on the self in the pursuit of sporting achievement - leads to its increasing sophistication. Of course, all people reflect on the impact of medical interventions on how they feel and make changes as they see fit (often in discussion with doctors), but athletes do this more continuously, more holistically, and evaluate the outcomes (i.e. their performance) more systematically. With these points in mind, we can begin to sketch out a research agenda for the sociology of sport, health and medicine.

\section{Defining a research agenda for the sociology of sport, health and medicine}

In line with what has been outlined above, a progressive research agenda for sport, health and medicine would twin elements of good practice from both the sociology of sport and the sociology of medicine. It would be structured to connect with the central themes of the sociology of medicine while retaining the distinctive aspects which stem from a sport-specific application. Accordingly, I identify four general categories, suggesting extensions to existing bodies of work and the exploration of new areas of study.

First, it is important that social scientists of sport continue to develop research on the health and illness experiences of sportspeople. While we have relatively extensive coverage of the way elite performers respond to pain and injury, a range of additional studies could be conducted. To this end research might extend the recent works which identify diagnosis (Jutel, 2009) as a key stage marking the transition from health to illness and a key marker in the exercise of the authority of clinician over patient. We could explore further the importance of trust (Mechanic \& Meyer 2000) in the patient-clinician relationship and the importance of 
practice context for patient experience and clinician control. We could explore in more detail the experiences of particular conditions, distinguishing between patients' experiences of acute and chronic conditions (we have largely only investigated chronic conditions to date), and 'invisible' injuries such as concussion (Malcolm, 2009) and asthma (Allen-Collinson \& Owton 2012) with not only visible but sometimes highly public conditions such as broken bones. By conceptualizing illness more broadly, we could explore experiences of asymptomatic populations exposed to the 'policing' function of sports medicine. Athletes are routinely screened for drug use, and certain populations are exposed to both gender testing and (dis-)ability classification which regulates the scope of legitimate participation, yet we know relatively little about how this is experienced by individuals. The value of such research will increase as routine cardiac screening becomes more common in sport, and drawing on the emerging literature on the sociology of screening (Armstrong \& Eborall 2012) would illustrate the potential of such programmes to both create as well as alleviate ill-health. Moreover, we could extend our understanding of how sports pain and injury affects the everyday exerciser, what healthcare provision is available to this group, and how perceived limitations in that provision lead people to undertake their own healthcare innovation. This area is markedly under-researched. We understand that injury and related perceptions of fitness are among the primary reasons why people cease to take part in exercise, but know little about the specifics of that process and thus what could be done to reduce exercise withdrawal.

A second area to develop is the critique of the sport-health ideology, and the context of physical activity health promotion. While the logic of the association has been effectively problematized, there is a broader sociological critique of health promotion - focussing on structure, surveillance and consumption (Bunton et al., 1995) - which could be adapted and applied to the context of sport. Structurally health promotion can be criticized for failing to 
recognize the importance of material (dis-)advantage in mediating lifestyle and disregarding the role of environmental conditions in contouring the choices that people can make. Consequently, health promotion campaigns not only lead to victim-blaming and stigmatization, but frequently perpetuate and reinforce inequalities and replicate gender and race stereotypes. Health promotion is also criticized for monitoring and regulating populations through surveillance. Individuals are 'profiled' into distinct social groups with new social identities constructed such that healthy living becomes not something one merely does, but part of a broader personal philosophy of continuous self-improvement. Health promotion extends the reach of medical surveillance into the populations' everyday life; something which consulting doctors alone could never achieve. Finally it can be argued that the blurring of health and consumer culture leads to the creation of distinct lifestyles which stratify society; in Bourdieu's terminology, a habitus which is both constituted by and constituting of social relations. This has implications for social (in-)equality, but also for the economic exploitation of populations 'coerced' into exercise regimes by state policies, yet primarily serviced by the commercial sector.

But this work should also recognize that sport holds a peculiar position in the broader health promotion strategies of contemporary governments. While the other main targets of health promotion - tobacco, alcohol and diet - are (where legally permitted) routinely advertised by their producers, sport is frequently used as a vehicle to promote the very products that health promotion campaigns seek to curb (see discussion of Waddington, 2000 above). Second, unlike the other targets of health promotion, the abilities of some sections of the population to participate in sport are relatively restricted, with some people simply unable to exercise as prescribed. Of course, there are some people who cannot cease tobacco and alcohol intake. Tellingly however their condition - addiction - has itself been medicalized, yet there is no comparable condition for exercise non-adherence. Third, while the public are 
largely persuaded to reduce their consumption of the other health promotion targets and so therefore have a fixed marker of individual 'achievement' (i.e. to stop smoking cigarettes), the public are persuaded to increase their physical activity, leading to an open-ended and non-specific marker of achievement. Physical activity is, therefore, an extreme of health promotion, a process by which, Lupton argues in The Health Imperative (1995), citizens come to voluntarily compel themselves to live 'healthy' lives. This constructs and normalizes a subject who is 'autonomous, directed at self-improvement, self-regulated, desirous of selfknowledge, a subject who is seeking happiness and healthiness' (Lupton, 1995, p. 11). Yet for the exerciser happiness and healthiness are imprecisely defined, elusive and therefore potentially unobtainable goals. Finally, uniquely for a health promotion target, increased exercise leads to a distinct and considerable health burden for the individual and state (sports injuries and related work absenteeism). We therefore need to explore the consequences of such policies in their entirety, encompassing those currently injured and those who no longer exercise due to sport-induced injury.

Third, social scientists need to focus on research which exposes the social processes and in particular inequalities - that shape the patterns and perceptions of health and illness. We have some work which identifies the very different healthcare provision male and female elite athletes receive in certain contexts (Kotarba, 2012), but we have little or no information about how class, ethnicity, and disability contour this social experience. Moreover, while research has indicated that males and females have very similar experiences of sports injury (see above), this requires further investigation because it is a conclusion which contradicts research from the sociology of medicine more generally. Given the widespread quantitative and qualitative gender inequalities in medicine and healthcare (Annandale, 1998) it seems hardly credible that there are no relevant gender differences that require explanation. We haven't, for instance, sought to explore the gendered nature of clinician-athlete interactions, 
how male and female athletes relate to male and female healthcare providers. One indication of the potential differences in this respect is the much publicized difference between male and female rates of ACL injury. There are politically sensitive concerns about undertaking research which could perpetuate historical ideas about female frailty (Vertinsky, 1990), but if social scientists of sport fail to explore the cultural parameters which influence this particular health risk, a bio-medical explanation which focuses on physiological difference between genders will predominate.

Research exploring the social processes that shape health and illness patterns could also explore the inequalities in the provision of sports medicine for nationally funded sportspeople and the general public. London 2012 provided a considerable boost for sport and exercise medicine in the UK, and a central legacy pledge was to increase public participation in sport. But have the public also benefitted from a similar medical premium? Is everyday access to sports medicine, like the games themselves, publicly funded or has the economic burden of an increase in the demand for sports healthcare been met by individuals and thus swelled the commercial medical sector? And we could also start to explore aspects of the global inequality of sports medicine, how unequal provision impacts on competitive sports success, and the effects of a cultural intermingling of different and competing forms of medicine (e.g. the interest in Chinese herbal medicine expressed by western athletes). Will we, moreover, see the development of a global sports medicine labour market in much the same way there has been for elite athletes?

Fourthly and finally we should not lose sight of the way in which the context specificities of sport shape medical provision, and indeed the way this feeds back into public health provision more widely. For instance, one of the key characteristics of elite sport is its high media profile. Sports medicine, by association, is therefore particularly visible to the general public and stories about athletes' health, illness, recovery and medical treatment are 
broadly consumed. How does this affect the way people perceive medicine, its successes and failures, and the entitlement of ordinary people to receive similar treatment? Related to this, sport showcases the introduction of technological innovations in social life and the 'cyborgification' of athletes in particular. How will this influence the public's perceptions of the possibilities of medical technology, the scope of medicine as it moves 'beyond therapy' (Kondo \& McNamee 2012)? The highest media profile for sport is produced by mega events and these open up further important questions for a sociology of sport, health and medicine. The role of sponsorship has already been noted, and others have explored the health legacies that are now claimed for events such as the London 2012 Olympics. But how does the hosting of such events impact upon public healthcare provision? Paraschak (2012) has discussed the impact of a relative small event on a relatively small Canadian community, but there is work to be done which identifies how the considerable diversion of medical resources which bidding cities must promise in order to win the right to host particular events impacts upon public healthcare more widely (Malcolm \& Mansfield forthcoming).

\section{Conclusion}

There are then a myriad of research opportunities for social scientists of sport to develop. The areas identified in the previous section do not represent an exhaustive list, but are designed to provoke and inspire the sociological imagination (Wright Mills, 1970) for it seems clear that societal trends and the funding priorities of research councils around the world will mean that the sport, health and medicine agenda is prominent on our horizons for the foreseeable future. Social scientists must (continue to) be involved in this. It is our unique contribution to provide the critical element for our sports science/kinesiology colleagues who might otherwise follow these research leads without questioning the broader context in which they 
are socially constructed, the unintended as well as intended consequences, the social harm as well as benefit.

But in doing so we should also be cognisant of some of the threats that this trajectory poses to our professional status. Multidisciplinarity can be a threat to social scientists whose work is frequently relegated within the epistemological hierarchy which prioritizes the positivistic methods of the natural sciences (Andrews, 2008), and subsequently misunderstood or disparaged by our physiologically-oriented colleagues. In this regard, while we should seek to learn from the sociology of medicine we should also be aware of some of the concerns expressed in that community. For instance Nettleton (2007, p. 2409) has argued that subservience to medicine has meant that the sociology of medicine retains a 'problem solving' orientation which threatens the intellectual rigour of the subdiscipline. Consequently she has called for research to have greater theoretical orientation and for more non-applied research to be conducted. In pursuing the kind of research agenda outlined in this article, sociologists of sport should not betray the rigorous theoretical groundings which are a major achievement of our subdiscipline (Malcolm, 2012), and in particular our relatively sophisticated analyses of the theories of Elias, Bourdieu and Foucault which are of considerable relevance to a sociology of the body and its treatment by and objectification within medicine. A theoretically engaged enquiry and sensitivities towards both the structure of contemporary medicine and the particularities of sport will lead to a nuanced sport, health and medicine agenda that will both promote the social sciences of sport and enhance the human condition.

\section{References}

Albrecht, G., Fitzpatrick, R \& Scrimshaw, S. (2000). The Handbook of Social Studies of Health and Medicine. London: Sage. 
Andrews, D. (2008). Kinesiology's inconvenient truth and the physical cultural studies imperative. Quest, 60(1), 45-62.

Allen-Collinson, J. \& Owton, H. (2012). Take a deep breath: Asthma, sporting embodiment, the senses and 'auditory work'. International Review for the Sociology of Sport, DOI: 10.1177/1012690212463918.

Annandale, E. (1998). Gender inequalities and health status. In E. Annandale, The sociology of health and medicine: A critical introduction. Buckingham: Open University Press.

Armstrong, N. \& Eborall, H. (2012). The sociology of medical screening: Past, present and future. Sociology of Health and Illness, 34(2), 161-176.

Atkinson, M. F. (2007). Playing with fire: Masculinity and exercise supplements. Sociology of Sport Journal, 24(2), 165-186.

Berger, P. (1963). Invitation to Sociology. London: Pelican.

Berryman, J. (2010). Exercise is medicine: A historical perspective. Current Sports Medicine Reports, 9(4), 195-201.

Bundon, A. \& Clarke, L. (2012). 'Keeping us from breaking': Elite athletes' access to and use of complementary and alternative medicine. Qualitative Research in Sport, Exercise and Health, DOI: 10.1080/2159676X.2012.712986

Bunton, R., Nettleton, S. \& Burrows, R. (1995). The sociology of health promotion: Critical analyses of consumption, lifestyle and risk. London: Routledge

Diehl, K., Thiel, A., Zipfel, S., Mayer, J., Litaker, D. \& Schneider, S. (2012). How healthy is the behaviour of young athletes? A systematic literature review and meta-analyses. Journal of Sports Science and Medicine, 11, 201-220.

Edwards, S. \& McNamee, M. (2006). Why sports medicine is not medicine. Health Care Analysis, 14, 103-109.

House of Lords, Science and Technology Committee (2012). Sport and exercise science and medicine: building on the Olympic legacy to improve the nation's health. London: HMSO.

http://www.publications.parliament.uk/pa/ld201213/ldselect/ldsctech/33/3302.htm

Hughes, R. \& Coakley, J. (1991). Positive deviance among athletes: The implications of overconformity to the sport ethic. Sociology of Sport Journal, 8(4), 307-325. 
Illich, I. (1975). Medical Nemesis. London: Calder \& Boyars.

Jutel, A. (2009). Sociology of diagnosis: A preliminary review. Sociology of Health and Illness, 38(2), 387-399.

Kerr, R. (2012). Integrating scientists into the sports environment: A case study of gymnastics in New Zealand. Journal of Sport and Social Issues, 36(1), 3-24.

Kondo, Y. \& McNamee, M. (2012). Sports medicine beyond therapy: Genetic doping and enhancement. In D. Malcolm \& P. Safai (Eds) The social organization of sports medicine: Critical socio-cultural perspectives (305-326). New York: Routledge.

Kotarba, J. (1983). Chronic Pain. Beverley Hills, Calif.: Sage.

Kotarba, J. (2001). Conceptualizing sports medicine as occupational health care: Illustrations from professional rodeo and wrestling. Qualitative Health Research, 11, 766-779.

Kotarba, J. (2012). Women’s professional athletes’ injury care: The case of women’s football. In D. Malcolm \& P. Safai (Eds) The social organization of sports medicine: Critical socio-cultural perspectives (107-125). New York: Routledge.

Liston, K., Reacher, D., Smith, A., \& Waddington, I. (2006). Managing pain and injury in non-elite rugby union and rugby league: A case study of players at a British university. Sport in Society, 9, 388-402.

Loland, S., Skirstad, B. and Waddington, I. (Eds) (2006). Pain and injury in sport: Social and ethical analysis. London: Routledge.

Lupton, D. (1995). The imperative of health: Public health and the regulated body. London: Sage.

Malcolm, D. (2006). Unprofessional practice? The status and power of sports physicians. Sociology of Sport Journal, 23(4), 376-395.

Malcolm, D. (2009). Medical uncertainty and clinician-athlete relations: The management of concussion injuries in rugby union. Sociology of Sport Journal, 26(2), 191-210.

Malcolm, D. (2012). Sport and Sociology. London: Routledge.

Malcolm D. \& Mansfield, L. (forthcoming). The Olympic Movement, sport and health. In J. Baker, J-F. Thomas \& P. Safai (Eds) Health and elite sport: Is high performance sport a healthy pursuit? New York: Routledge. 
Malcolm, D. \& Safai, P. (2012). Introduction: The social science of sports medicine. In D. Malcolm \& P. Safai (Eds) The social organization of sports medicine: Critical sociocultural perspectives (1-23). New York: Routledge.

Malcolm, D. \& Scott, A. (2011). Professional relations in elite sport healthcare: Workplace responses to organizational change. Social Science \& Medicine, 72, 513-520.

Malcolm, D. \& Scott, A. (2013). Practical responses to confidentiality dilemmas in elite sports medicine. British Journal of Sports Medicine, doi:10.1136/bjsports-2012090974.

Malcolm, D. \& Sheard. K. (2002). 'Pain in the assets': The effects of commercialization and professionalization on the management of injury in English rugby union. Sociology of Sport Journal, 19(2), 149-169.

Martin, G. \& Finn, R. (2011). Patients as team members: opportunities, challenges and paradoxes of including patients in multi-professional health-care teams. Sociology of Health \& Illness, 33(7), 1050-1065.

Mechanic, D. \& Meyer, S. (2000) Concepts of trust among patients with serious illness. Social Science \& Medicine, 51, 657-688.

Messner, M. (1992). Power at play: Sport and the problems of masculinity. Boston: MA Beacon Press.

Naci, H. \& Ioannidis, J. (2013). Comparative effectiveness of exercise and drug interventions on mortality outcomes: metaepidemiological study. British Medical Journal, 347doi: http://dx.doi.org/10.1136/bmj.f5577

Nettleton, S. (2006). The sociology of health and illness. Cambridge: Polity.

Nettleton, S. (2007). Retaining the sociology in medical sociology. Social Science \& Medicine, 65, 2409-2412.

Nixon, H.L. II. (1992). A social network analysis of influences of athletes to play with pain and injury. Journal of Sport and Social Issues, 16(2), 127-135.

Paraschack, V. (2012). Public health, elite sport, and "risky behaviors" at the Canada Winter Games. In D. Malcolm \& P. Safai (Eds) The social organization of sports medicine: Critical socio-cultural perspectives (126-149). New York: Routledge. 
Piggin, J. \& Bairner, A. (forthcoming). The global physical inactivity pandemic: An analysis of knowledge production. Sport, Education and Society.

Pike, E. (2005). Doctors just say 'rest and take ibuprofen': A critical examination of the role of 'non-orthodox' health care in women's sport. International Review for the Sociology of Sport, 40(3), 201-219.

Pringle, R. \& Markula, P. (2005). No pain is sane after all: A Foucauldian analysis of masculinities and men’s rugby experiences. Sociology of Sport Journal, 22(4), 472497.

Roderick, M. (2006). The Work of Professional Football. London: Routledge.

Safai, P. (2003). "Healing the body in the 'culture of risk:' Examining the negotiation of treatment between sports medicine clinicians and injured athletes in Canadian intercollegiate sport. Sociology of Sport Journal, 20(2), 127-146.

Safai, P. (2007). A critical analysis of the development of sport medicine in Canada, 19551980. International Review for the Sociology of Sport, 42(3), 321-341.

Safai, P. (2008). Sport and health. In B. Houlihan (Ed.) Sport and society: A student introduction (155-172). London: Sage ( $2^{\text {nd }}$ edition).

Scambler, G. (2005). Sport and society: History, power and culture. Maidenhead: Open University Press.

Scott, A. (2012). Sport and exercise medicine's professional project: The impact of formal qualifications on the organization of British Olympic medical service. International Review for the Sociology of Sport, doi:10.1177/1012690212461909

Sparkes, A. \& Smith, B. (2002). Men, sport, spinal chord injury and the construction of coherence: narrative practice in action. Qualitative Research, 2(2), 143-171.

Theberge, N. (2007). 'It's not about health, it’s about performance.' Sport medicine, health and the culture of risk in Canadian sport. In J. Hargreaves \& P. Vertinsky (Eds) Physical Culture, Power and the Body (176-194). London: Routledge.

Theberge, N. (2008). The integration of chiropractors into healthcare teams: A case study from sports medicine. Sociology of Health \& Illness, 30(1), 19-34. 
Theberge, N. (2009). 'We have all the bases covered.' Constructions of professional boundaries in sport medicine. International Review for the Sociology of Sport, 44(3), 265-282.

Thing, L. (2012). Docile bodies or reflexive users? On the individualization of medical risk in sports. In D. Malcolm \& P. Safai (Eds) The social organization of sports medicine: Critical socio-cultural perspectives (187-203). New York: Routledge.

Turner, B.S. (1995). Medical power and social knowledge. London: Sage (2 ${ }^{\text {nd }}$ edition).

Vertinsky, P. (1990). The eternally wounded woman: Women, doctors and exercise in the late nineteenth century. Manchester: Manchester University Press.

Waddington, I. \& Murphy, P. (1992). Drugs, sport and ideologies. In E. Dunning \& C. Rojek (Eds) Sport and leisure in the civilizing process (36-64). London: Macmillan.

Waddington, I. \& Roderick, M. (2002). The management of medical confidentiality in English professional football clubs: Some ethical problems and issues. British Journal of Sports Medicine, 36, 118-123.

Waddington, I. (2000). Sport, health and drugs: A critical sociological investigation. London: E \& FN Spon.

Waddington, I. (2012). Sports medicine, client control and the limits of professional autonomy. In D. Malcolm \& P. Safai (Eds) The social organization of sports medicine: Critical socio-cultural perspectives (204-226). New York: Routledge.

Walk, S. (1997). Peers in pain: The experiences of student athletic trainers. Sociology of Sport Journal, 14(1), 22-56.

Wilkinson, M. \& Marmot, R. (Eds) (2003). The social determinants of health. Oxford: OUP.

Wright Mills, C. (1970). The sociological imagination. London: Penguin.

Young, K. (1993). Violence, risk and liability in male sports culture. Sociology of Sport Journal, 10(4), 373-396.

Young, K. (Ed.) (2004). Sporting bodies damaged selves: Sociological studies of sports related injuries. Oxford: Elsevier Press.

Young, K., \& White, P. (1993). Sport, physical danger and injury: The experiences of elite women athletes. Journal of Sport \& Social Issues, 19(1), 45-61. 
Young, K., White, P. \& McTeer, W. (1994). Body talk: Male athletes reflect on sport, injury and pain. Sociology of Sport Journal, 11(2), 175-194.

Zola, I. (1972). Medicine as an institution of social control. Sociological Review, 20, 487-504.

\section{Notes}

${ }^{1}$ http://www.acsm.org/access-public-information/articles/2012/01/09/exercise-is-medicine-a-focus-onprevention accessed $14^{\text {th }}$ January 2014

${ }^{2}$ It should be noted that three terms are used to describe this area of scholarship: medical sociology, the sociology of medicine, and the sociology of health and illness. Each reflects a slightly different orientation and/or theoretical grounding. Medical sociology is normally seen as a term for the application of sociology to medical matters driven by the research agenda of medicine, whereas sociology of medicine implies a more critical approach to medicine, seeking to examine medicine as a social institution rather than simply working for the advancement of the productivity of medicine. The sociology of health and illness places greater emphasis on the public receivers (patients) of medical care and thus is characterized by more frequent use of theories of the sociology of the body. For reasons of ease just one term - sociology of medicine - will be used in this article.

${ }^{3}$ See http://www.issa.otago.ac.nz/about.html

${ }^{4}$ http://www2.asanet.org/medicalsociology/ accessed $14^{\text {th }}$ January 2014.

\footnotetext{
${ }^{5}$ Medicalization refers to medicine's increasing influence and depth of penetration into areas of social life which were previously beyond the scope of the profession's domain. Some have described this as a form of imperialism and pointed to the development of medicine as a tool of social control. Illich (1975) further argued that medicalization meant that the profession not only cured illness and relieved suffering, but it created iatrogenesis, or medically caused illness.
} 